\title{
Clinical Features of Untreated Type 2 Macular Telangiectasia and Efficacy of Anti-Vascular Endothelial Growth Factor Therapy in Macular Neovascularization
}

\author{
(1) Müge Çoban Karataş*, (1) Gürsel Yılmaz**, (1) Aslıhan Yüce Sezen**, (1) Çağla Sarıtürk*** \\ *Niğde Ömer Halisdemir University Faculty of Medicine, Department of Ophthalmology, Niğde, Turkey \\ **Başkent University Faculty of Medicine, Department of Ophthalmology, Ankara, Turkey \\ ***Başkent University Adana Clinic and Research Center, Division of Biostatistics, Adana, Turkey
}

\begin{abstract}
Objectives: To compare best corrected visual acuity (BCVA), central macular thickness (CMT), and central choroidal thickness (CCT) in patients with type 2 macular telangiectasia (MacTel 2) and a control group and to evaluate the efficacy of intravitreal anti-vascular endothelial growth factor (anti-VEGF) treatment in MacTel 2 patients with macular neovascularization (MNV).

Materials and Methods: We conducted a retrospective chart review of consecutive MacTel 2 patients who underwent a full ophthalmologic examination including BCVA and dilated fundus examination with slit-lamp biomicroscopy, fluorescein angiography, and optical coherence tomography imaging at baseline and follow-up visits. BCVA, CMT, and CCT were compared between all identified patients ( $n=26)$ and a control group $(n=30)$. A subgroup analysis was performed among eyes with MNV $(n=7)$ before and after treatment. Results: CMT and CCT were significantly lower in the MacTel 2 group compared to the control group. Forty-one treatment-naive eyes without MNV proliferation showed no significant change in BCVA, CMT, or CCT during follow-up. Eight eyes of 7 MacTel 2 patients developed MNV during follow-up. All of the patients were treated with intravitreal anti-VEGF.

Conclusion: It is important to closely follow MacTel 2 patients for MNV development. To avoid adverse effects, we prefer to monitor patients who have not yet developed MNV. Patients with proliferative MacTel 2 with decreasing visual function may benefit from intravitreal anti-VEGF treatment.
\end{abstract}

Keywords: Macular telangiectasia, macular neovascularization, anti-VEGF treatment

\section{Introduction}

Idiopathic juxtafoveal telangiectasia (IMT) is associated with foveal thinning, crystalline deposits in the macula, telangiectatic vascular changes with leakage, and macular neovascularization (MNV). ${ }^{1}$ Gass and Blodi ${ }^{2}$ classified IMT into stages and groups. Of the three groups, type 2 is the most common. ${ }^{3}$ Macular telangiectasia type 2 (MacTel 2) is an acquired bilateral disease that causes reduced visual acuity and metamorphopsia, occurring most commonly in middle-aged men and women. ${ }^{4}$ Although it has been shown that luteal pigment loss may be involved in the pathogenesis of the disease, ${ }^{5}$ Müller cell dysfunction is known to play critical role in the pathogenesis. ${ }^{6}$ Visual loss may occur due to atrophy of the foveal photoreceptors and foveal structural changes. ${ }^{2,3,4,5,6} \mathrm{MNV}$ may occur in some patients and can cause

Address for Correspondence: Müge Çoban Karataş, Niğde Ömer Halisdemir University Faculty of Medicine, Department of Ophthalmology, Niğde, Turkey E-mail: bkaratas99@hotmail.com ORCID-ID: orcid.org/0000-0002-7903-5075

Received: 22.03.2021 Accepted: 25.11.2021

Cite this article as: Çoban Karataş M, Y1lmaz G, Yüce Sezen A, Sarıtürk Ç. Clinical Features of Untreated Type 2 Macular Telangiectasia and Efficacy of AntiVascular Endothelial Growth Factor Therapy in Macular Neovascularization. Turk J Ophthalmol 2022;52:45-49

${ }^{\circledR}$ Copyright 2022 by Turkish Ophthalmological Association Turkish Journal of Ophthalmology, published by Galenos Publishing House. 
serious visual deterioration. ${ }^{2,7}$ Various therapeutic approaches have been used in patients with MacTel 2 complicated with $\mathrm{MNV}$, including laser photocoagulation, ${ }^{8}$ photodynamic therapy, ${ }^{9}$ transpupillary thermotherapy, ${ }^{10}$ intravitreal triamcinolone, ${ }^{11}$ and anecortave acetate. ${ }^{12}$ Recently, anti-vascular endothelial growth factor (anti-VEGF) therapy has become the preferred treatment option. ${ }^{13,14}$

The aim of our study was to compare best corrected visual acuity (BCVA), central macular thickness (CMT), and central choroidal thickness (CCT) in MacTel 2 and a control group and to evaluate the efficacy of intravitreal anti-VEGF therapy in MacTel 2 patients with MNV.

\section{Materials and Methods}

This retrospective study included a series of consecutive patients with MacTel 2 who were examined between January 2012 and December 2019 in our ophthalmology department. Eyes with ocular pathology causing decreased vision, such as diabetic retinopathy or age-related macular degeneration, were excluded from the study. MacTel 2 patients with at least 6 months of follow-up were included in the study. An age-matched control group was selected from healthy patients with no systemic disease. This study was approved by Baskent University Institutional Review Board (project no:19/63) and informed consent was obtained from each subject.

Forty-nine eyes of $26 \mathrm{MacTel} 2$ patients and 60 eyes of 30 healthy control patients were included in the study. All patients underwent a full ophthalmologic examination including dilated fundus examination with slit-lamp biomicroscopy, BCVA, color fundus photography, fluorescein angiography (FA; Zeiss Visucam 500), and optical coherence tomography (OCT; Heidelberg Engineering, Heidelberg, Germany) imaging at baseline and follow-up visits. The clinical criteria for the diagnosis of MacTel 2 included small intraretinal crystalline deposits, parafoveal graying of the retina, and presence of pigment clumps and right angle venules. ${ }^{1}$ Parafoveal telangiectatic capillaries observed in the mid-arteriovenous phase and late phase leakage surrounding the fovea is diagnostic in FA. Submacular neovascular membrane was confirmed on OCT imaging and FA. Signs of MNV include increased CMT on OCT, presence of retinal hemorrhage, or decline in visual acuity from baseline.

BCVA, CMT, and CCT were compared between all identified patients $(n=26)$ and the control group $(n=30)$. A subgroup analysis was performed among eyes with MNV $(n=7)$ before and after treatment.

\section{Statistical Analyses}

Statistical analysis of the data was performed using SPSS version 23.0 package program (IBM Corp, Armonk, NY). Categorical measurements were summarized as number and percentage, continuous measurements as mean and standard deviation (or median and minimum-maximum where necessary). Chi-square test or Fisher test statistic was used to compare categorical variables. Data distribution was checked for comparison of continuous measurements between groups; Mann-
Whitney $U$ test was used for non-normally distributed and Student's t test for normally distributed parameters. Wilcoxon test was used to compare values before and after treatment. The statistical significance level was 0.05 in all tests.

\section{Results}

There were 23 women and 3 men in the Mac'Tel 2 group and 30 women in the control group. The mean age of the MacTel 2 group was 65.54 years (range 53-83, median 65) and that of the control group was 61.86 years (range: 47-77, median: 62). There was no statistically significant difference in age and gender between the groups. Mean follow-up time was 33.6 months (range: 6-72).

CMT and CCT were significantly lower in the MacTel 2 group compared to the control group (Figures 1 and 2). Mean CMT was $243.55 \mu \mathrm{m}$ (range: 161-318, median: 241) in the MacTel 2 group and $263.58 \mu \mathrm{m}$ (range: 225-295, median: 263) in the control group $(\mathrm{p}=0.0001)$. Mean CCT in the MacTel 2

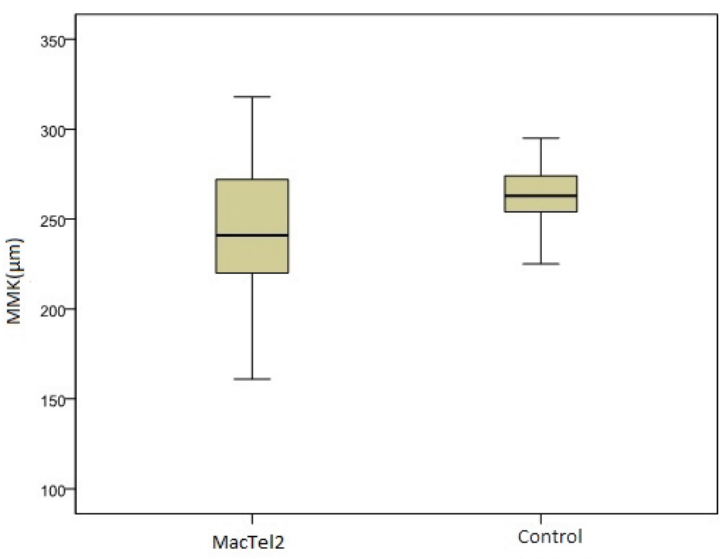

Figure 1. Central macular thickness (CMT) was significantly lower in the MacTel 2 group compared to the control group ( $\mathrm{p}=0.0001)$

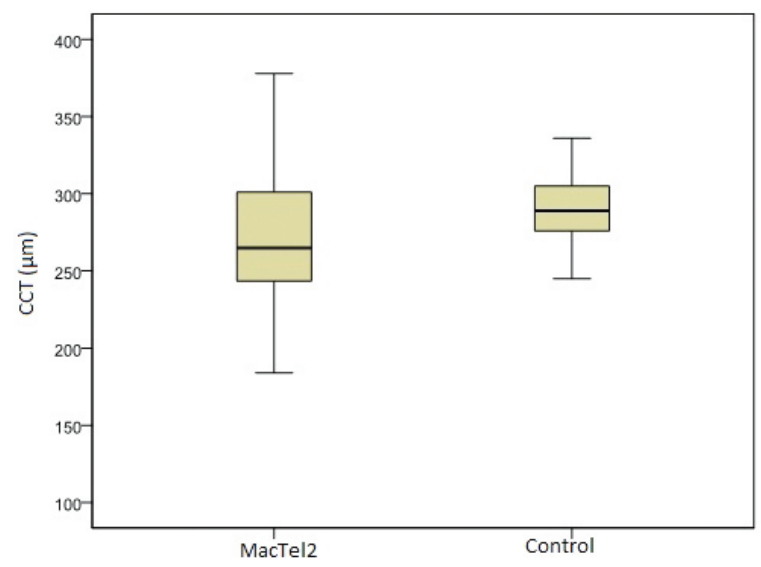

Figure 2. Central choroidal thickness (CCT) was significantly lower in the Mac'Tel 2 group compared to the control group $(\mathrm{p}=0.014)$ 


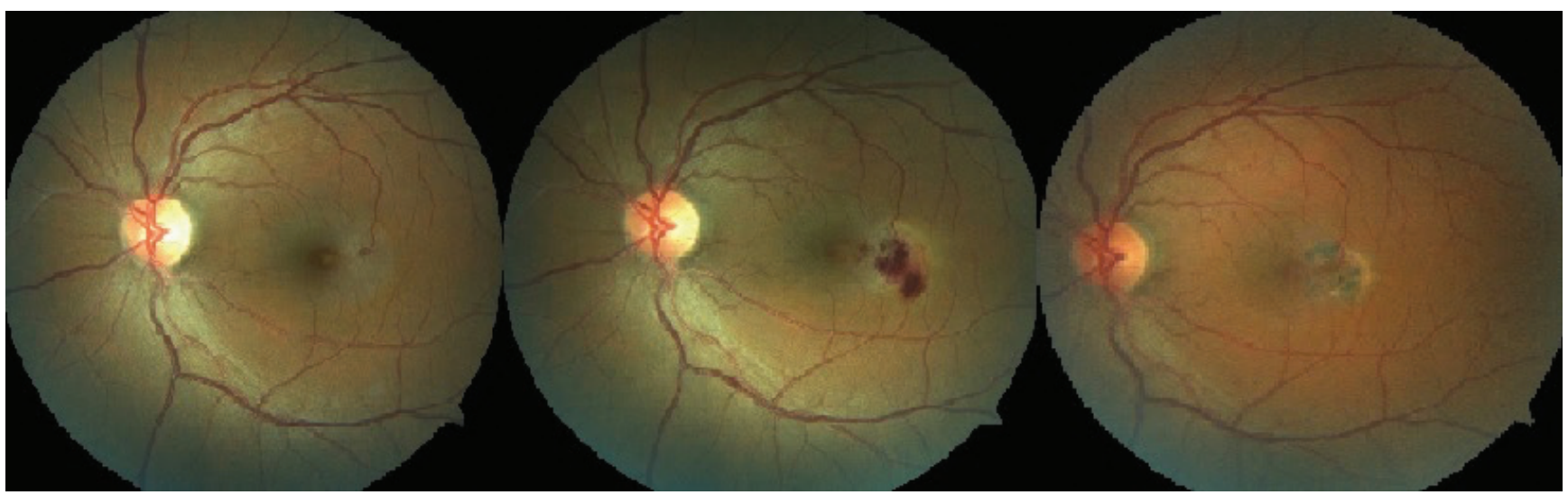

Figure 3. Fundus photograph of the left eye of a 53-year-old female patient showed temporal parafoveal foci of retinal pigment epithelium hyperplasia with foveal pigmentary change (left image). She presented to the clinic with acute vision loss 1 year after the diagnosis (middle image) due to retinal hemorrhages and choroidal neovascularization. The right image was taken after 3 doses of anti-VEGF treatment and shows regression of the macular neovascularization

and control groups was $273.04 \mu \mathrm{m}$ (range 184-378, median 265) and $289.83 \mu \mathrm{m}$ (range: 245-336, median: 289), respectively $(\mathrm{p}=0.014)$.

The 41 treatment-naive eyes without MNV showed no significant change in BCVA ( $\mathrm{p}=0.058)$, CMT $(\mathrm{p}=0.304)$, or CCT $(\mathrm{p}=0.062)$ during follow-up.

Eight eyes of 7 MacTel 2 patients developed MNV during follow-up (Figure 3). All of the patients were treated with intravitreal anti-VEGF injection. Six eyes were treated with intravitreal ranibizumab (Lucentis; Genentech, Inc, South San Francisco, CA) and two were treated with aflibercept (Eylea; Regeneron, Tarrytown, New York) (Figure 4a-c). CMT and CCT decreased slightly after treatment but not significantly. Mean CMT before treatment was $252.33 \mu \mathrm{m}$ (range 216-297, median 250.16) and after treatment $237.33 \mu \mathrm{m}$ (range 215-254, median 237.33) ( $\mathrm{p}=0.123)$. Mean CCT before treatment was 279.12 $\mu \mathrm{m}$ (range 210-325, median 285.5) and after treatment $262 \mu \mathrm{m}$ (range 235-288, median 262) $(\mathrm{p}=0.123)$. Best corrected visual acuity improved in 5 eyes, decreased in 2 eyes, and remained the same in 1 eye.

\section{Discussion}

MacTel 2 is a neuroretinal degenerative condition with vascular involvement, telangiectasia, and deeper retinal vessel proliferation. ${ }^{2,7,15}$ Müller cells play a role in its pathogenesis. ${ }^{6,15,16}$ Spectral-domain OCT reveals hyperreflective spots in the external parafoveal retinal layers in the absence of FA findings. These hyperreflective spots are due to nonspecific neurodegenerative development. ${ }^{17}$ Late FA leakage occurs before capillary dilation. ${ }^{2}$ Gass and Oyakawa ${ }^{16}$ also emphasized in their study that retinal fluorescein dyeing occurs before capillary dilation. Central vision loss may occur as a result of photoreceptor atrophy without macular edema. ${ }^{15}$ The primary impairment in Mac'Tel 2 is in Müller cells or parafoveal neural cells. The disease does not involve the deep external retinal juxtafoveal capillaries. ${ }^{15}$ Late FA leakage is not due to increased retinal vascular permeability but
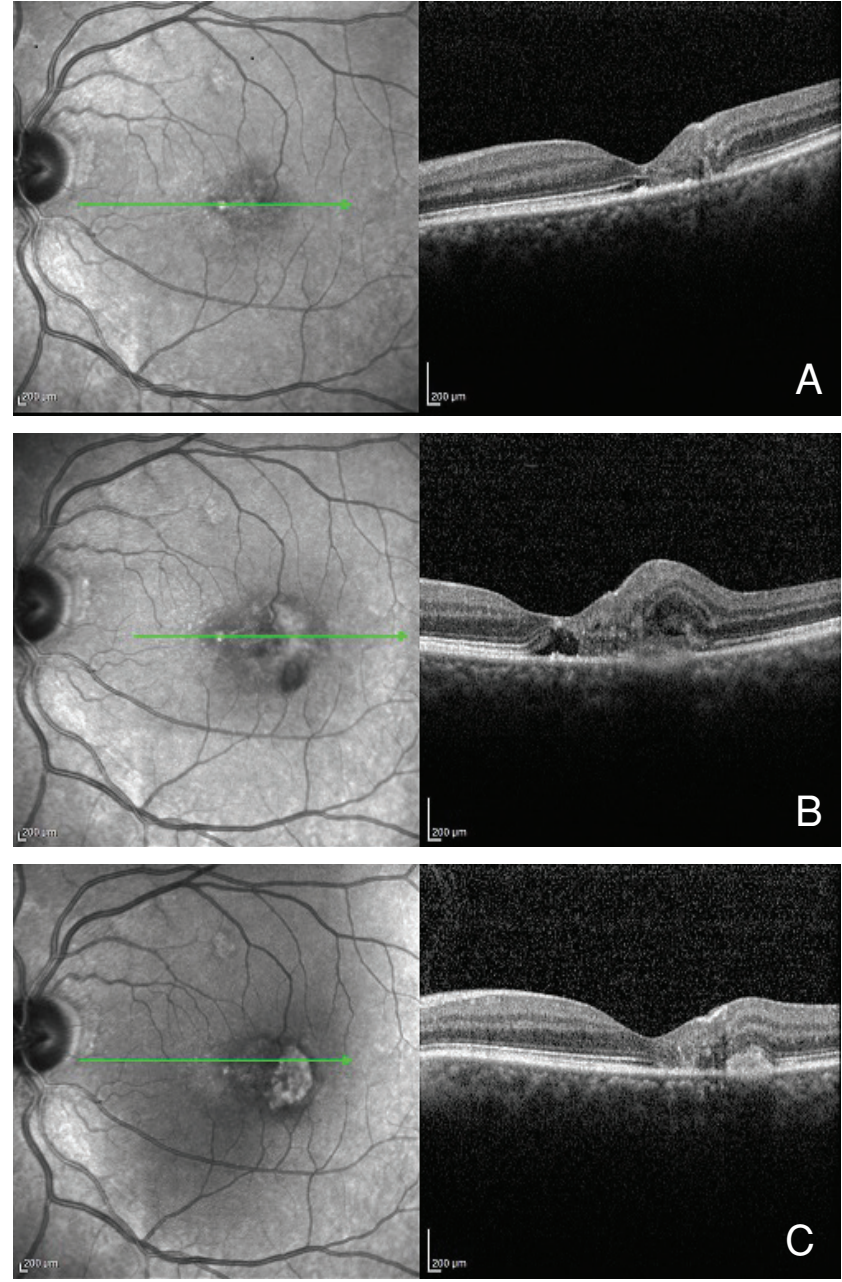

Figure 4. Optical coherence tomography and fundus photographs of the same MacTel 2 patient showing small intraretinal crystalline deposits (A). During follow-up, the patient's vision decreased due to macular neovascular membrane with active choroidal neovascularization (B). After intravitreal anti-VEGF therapy, her macular lesion regressed and the fluid resolved, with improved visual acuity $(C)$ 
is a result of damaged retinal cells, intracellular dye diffusion, and extracellular matrix staining. ${ }^{16,18}$ Clinicopathologic studies have shown that rod and cone photoreceptors in the central macular area are preserved, whereas Müller cells are reduced. ${ }^{6}$

In patients who develop MNV, the role of VEGF molecules in the pathogenesis continues to be controversial. Yanuzzi et al. ${ }^{7}$ proposed that endothelial cell degeneration may be the triggering factor of a vasogenic mechanism without ischemia and inflammation. Some investigators suggested that endothelial cell degeneration may be initiated by Müller cell dysfunction. ${ }^{19,20}$ Green et al. ${ }^{21}$ emphasized that retinal hypoxia due to endothelial degeneration and capillary structural disruption may increase angiogenesis and VEGF release. Spaide et al. ${ }^{22}$ mentioned that retinal-choroidal anastomoses were commonly observed in eyes with MacTel 2 without MNV using projection-resolved OCT angiography. This study suggests MacTel 2 is more than just a neurodegenerative disease with secondary abnormalities, as the choroid may be involved in the disease process.

Although some authors have stated that choroidal thickness did not differ between eyes with MacTel 2 and age-matched healthy subjects, ${ }^{23,24}$ in our study we determined that CMT and CCT were lower in the MacTel 2 group compared to the control group in long-term follow-up. This may be due to the neuroretinal degenerative nature of the disease, and MacTel 2 may also include abnormalities involving the choroid, though these are likely minor in comparison to the predominant retinal changes. ${ }^{22,25}$ Eight eyes (16.3\%) of 7 patients developed MNV. CCT and CMT were reduced in all eyes after anti-VEGF treatment (mean 1.87 injections, range 1-3, median 2). In 5 eyes, vision improved by more than 2 lines.

In another study including 25 eyes of 20 patients with MNV membrane secondary to MacTel type 2, patients received an average of 8.4 injections over 3 years of follow-up. ${ }^{13}$ Intravitreal anti-VEGF monotherapy appears to be safe and effective in Mac'Tel 2 patients who develop MNV.

MacTel 2 patients without MNV in our series received no treatment and showed no statistically significant change in BCVA, CMT, or CCT during follow-up. It was reported previously that intravitreal anti-VEGF therapy for macular telangiectasia without MNV was effective in reducing macular thickness but did not improve visual acuity. ${ }^{26,27,28,29} \mathrm{~A}$ recent study indicated that anti-VEGF treatment might even have an adverse effect on the retinal neurodegenerative process in patients with nonproliferative MacTel 2 because of VEGF's role in the maintenance of cones and Müller cells. ${ }^{30}$

\section{Study Limitations}

The most important limitations of our study are that it was retrospective and included a small number of patients.

\section{Conclusion}

Patients with Mac'Tel 2 must be closely monitored for the development of MNV. To date, there is no evidence for effective treatment of nonproliferative MacTel 2. ${ }^{30,31}$ We prefer follow-up without treatment for patients who have not developed MNV to avoid potential adverse effects. Intravitreal anti-VEGF therapy may be beneficial for patients with proliferative MacTel 2 and declining visual acuity. ${ }^{31}$

Ethics

Ethics Committee Approval: Baskent University Medicine Faculty (KA 19/63).

Informed Consent: Obtained.

Peer-review: Externally and internally peer reviewed.

\section{Authorship Contributions}

Surgical and Medical Practices: G.Y., A.Y.S., M.Ç.K., Concept: G.Y., M.Ç.K., Design: G.Y., M.Ç.K., Data Collection or Processing: A.Y.S., M.Ç.K., Analysis or Interpretation: M.Ç.K., Ç.S., G.Y., Literature Search: M.Ç.K., Writing: M.Ç.K. Conflict of Interest: No conflict of interest was declared by the authors.

Financial Disclosure: The authors declared that this study received no financial support.

\section{References}

1. Narayanan R, Chhablani J, Sinha M, Dave V, Tyagi M, Pappuru RR, Kuppermann BD. Efficacy of antivascular endothelial growth factor therapy in subretinal neovascularization secondary to macular telangiectasia type 2 . Retina. 2012;32:2001-2005.

2. Gass JD, Blodi BA. Idiopathic juxtafoveal telangiectasis. Update of classification and follow up study. Ophthalmology. 1993;100:1536-1546.

3. Narayanan R, Majji AB, Hussain N, Hussain A, Jalali S, Mathai A, Shah VA. Characterization of idiopathic macular telangiectasia type 2 by fundus fluorescein angiography in Indian population. Eur J Ophthalmol. 2008; 18:587-590.

4. Charbel Issa P, Gillies MC, Chew EY, Bird AC, Heeren TF, Peto T, Holz FG, Scholl HP. Macular telangiectasia type 2. Prog Retin Eye Res. 2013;34:49-77.

5. Charbel Issa P, van der Veen RL, Stijfs A, Holz FG, Scholl HP, Berendschot TT. Quantification of reduced macular pigment optical density in the central retina in macular telangiectasia type 2. Exp Eye Res. 2009;89:25-31.

6. Powner MB, Gillies MC, Tretiach M,Scott A, Guymer RH, Hageman GS et al. Perifoveal müller cell depletion in a case of macular telangiectasia type 2 . Ophthalmology. 2010;117:2407-2416.

7. Yanuzzi LA, Bardal AM, Freund KB, Chen KJ, Eandi CM, Blodi B. Idiopathic macular telangiectasia. Arch Ophthalmol. 2006;124:450-460.

8. Park DW, Schatz H, Mc Donald HR, Johnson RN. Grid laser photocoagulation for macular edema in bilateral juxtafoveal telangiectasis. Ophthalmology. 1997;104:1838-1846.

9. Potter MJ, Szabo SM, Chan EY, Morris AH. Photodynamic therapy of a subretinal neovascular membrane in type $2 \mathrm{~A}$ idiopathic juxtafoveal retinal telangiectasis. Am J Ophthalmol. 2002;133:149-151.

10. Nachiappan K, Shanmugam MP. Treatment of CNVM secondary to idiopathic juxtafoveal retinal telangiectasis by transpupillary thermotherapy. Am J Ophthalmol. 2005;139:577-578.

11. Alldredge CD, Garretson BR. Intravitreal triamcinolone for the treatment of idiopathic juxtafoveal telangiectasis. Retina. 2003;23:113-116.

12. Eandi CM, Ober MD, Freund KB, Klais CM, Slakter JS, Sorenson JA, Yannuzzi LA. Anecortave actate fort the treatment of idiopathic perifoveal telangiectasia: a pilot study. Retina. 2006;26:780-785.

13. Toygar O, Matthew G, Guess M, Youssef D, Miller D. Long-term outcomes of intravitreal bevacizumab theraphy for subretinal neovascularization secondary to idiopathic macular telangiectasia type 2. Retina. 2016;36:2150-2157.

14. Chatziralli IP, Sharma PK, Sivaprasad S. Treatment Modalities for Idiopathic Macular Telangiectasia: An Evidence-Based Systematic Review of the Literature. Semin Ophthalmol. 2017;32:384-394. 
15. Wu L, Evans T, Arevalo JF. Idiopathic macular telangiectasia type 2 (idiopathic juxtafoveolar retinal telangiectasis type 2A, Mac Tel 2. Surv Ophthalmol. 2013;58:536-559.

16. Gass JD, Oyakawa RT. Idiopathic juxtafoveolar retinal telangiectasis. Arch Ophthalmol. 1982;100:769-780.

17. Baumuller S, Charbel Issa P, Scholl HP, Schmitz-Valckenberg S, Holz FG. Outer retinal hypereflective spots on spectral-domain optical coherence tomography in macular telangiectasia type 2. Ophthalmology. 2010;117:2162-2168.

18. Gass JD. Histopathologic study of presumed parafoveal telangiectasis. Retina. 2000;20;226-227.

19. Tout S, Chan-Ling T, Hollander H, Stone J. The role of Müller cells in the formation of the blood-retinal barrier. Neuroscience. 1993;55:291-301.

20. Newman E, Reichenbach A. The Müller cell: a functional element of the retina. Trends Neorosci. 1996;19:307-312.

21. Green WR, Quigley HA, De la Cruz Z, Cohen B. Parafoveal retinal telangiectasis. Light and electron microscopy studies. Trans Ophthalmol Soc UK. 1980;100:162-170.

22. Spaide RF, Yanuzzi LA, Maloca PM. Retinal-choroidal anastomosis in macular telangiectasia type 2. Retina. 2018;38:1920-1929.

23. Chhablani J, Kozak I, Jonnadula GB, Venkata A, Narayanan R, Pappuru RR, Rao PS. Choroidal thickness in macular telangiectasia type 2. Retina. 2014;34:1819-1823.

24. Demir G, Cakir I, Alkin Z, Demircan A, Tulu B, Fazıl K. Evaluation of Choroidal Thickness in Patients with Proliferative and Non-Proliferative
Macular Telangiectasia Using Enhanced Depth Imaging Optical Coherence Tomography. Curr Eye Res. 2020;45:504-508.

25. Wang JC, Laíns I, Oellers P, Kim IK, Miller JW, Miller JB. Choroidal thickness and vascular density in macular telangiectasia type 2 using en face sweptsource optical coherence tomography. Br J Ophthalmol. 2019;103:1584-1589.

26. Roller AB, Folk JC, Patel NM, Boldt HC, Russell SR, Abramoff MD, Mahajan VB. Intravitreal bevacizumab for treatment of proliferative and nonproliferative type 2 idiopathic macular telengiectasia. Retina. 2011;31:1848-1855.

27. Do DV, Bressler SB, Cassard SD, Gower EW, Tabandeh H, Jefferys JL, Bressler NM. Ranibizumab for macular telengiectasia type 2 in the absence of subretinal neovascularization. Retina. 2014;34:2063-2071.

28. Charbel Issa P, Finger RP, Kruse K, Baumüller S, Scholl HP, Holz FG. Monthly ranibizumab for nonproliferative macular telangiectasia type 2: a 12-month prospective study. Am J Ophthalmol. 2011;151:876-886.

29. Toy BC, Koo E, Curkas C, Meyerle CB, Chew EY, Wong WT.Treatment of nonneovascular idiopathic macular telangiectasia type 2 with intravitreal ranibizumab:results of a phase II clinical trial. Retina. 2012;32:996-1006.

30. Kupitz EH, Heeren TF, Holz FG, Charbel Issa P. Poor long-term outcome of anti-vascular endotehelial growth factor therapy in nonproliferative macular telangiectasia type 2. Retina. 2015;35:2619-2626.

31. Charbel Issa P, Kupitz EH, Heeren TF, Holz FG. Treatment for macular telangiectasia type 2. Dev Ophthalmol. 2016;55:189-195. 